The use of real-time polymerase chain reaction with high resolution melting (real-time PCR-HRM) analysis for the detection and identification of pathogenetic and nonpathogenetic populations of the quarantine nematode Bursaphelenchus xylophilus

\author{
Wykorzystanie techniki real-time PCR-HRM do wykrywania \\ i odróżniania patogenicznych i niepatogenicznych populacji \\ kwarantannowego gatunku nicienia Bursaphelenchus xylophilus
}

\author{
Anna Filipiak*
}

\begin{abstract}
Summary
The quarantine nematode Bursaphelenchus xylophilus (pine wood nematode, PWN) is the causal agent of pine wilt disease in Asia and Europe. Great variation has been reported in the virulence level among populations of $B$. xylophilus. It is difficult to distinguish nematodes differing in virulence based on their morphology, therefore molecular biological techniques have been developed to identify virulence of various $B$. xylophilus populations. The real-time PCR-HRM was developed and evaluated as a method to detect and distinguish virulent and avirulent populations of B. xylophilus. A set of primers was designed to target the ITS- 2 region of rDNA. Reliability of the newly developed primer pair was examined and positively verified on eight virulent and two avirulent isolates of B. xylophilus originating from geographically distant localities in Europe and Asia. The results showed two distinct melting curve profiles related to each of the examined virulent forms. The results have demonstrated that the real-time PCR-HRM analysis is a rapid, simple and accurate method to detect and distinguish virulent and avirulent populations of B. xylophilus.
\end{abstract}

Key words: Bursaphelenchus xylophilus; nematode virulence; real-time PCR-HRM; pine wilt disease; quarantine nematode; detection

\title{
Streszczenie
}

Bursaphelenchus xylophilus jest czynnikiem sprawczym choroby więdnięcia sosny, doprowadzającym do zamierania drzew sosnowych na kontynencie azjatyckim, a od 1999 roku również w Europie. Dotychczasowe badania prowadzone nad patogenicznością nicienia B. xylophilus wykazały, że nie wszystkie izolaty tego szkodnika doprowadzają do zamierania drzew. W obrębie jego populacji stwierdzono występowanie patogenicznych, jak i całkowicie niepatogenicznych jego izolatów. Morfologiczne odróżnienie poszczególnych populacji charakteryzujących się różną patogenicznością jest całkowicie niemożliwe, dlatego poszukiwane są metody molekularne umożliwiające jak najbardziej precyzyjne ich odróżnienie. W przeprowadzonych badaniach do odróżniania patogenicznych i niepatogenicznych populacji tego kwarantannowego nicienia wykorzystano reakcję real-time PCR-HRM. W badaniach wykorzystano całkowite DNA patogenicznych oraz niepatogenicznych populacji $B$. xylophilus pochodzących z różnych rejonów świata. Dla populacji tych zaprojektowano własne startery, które amplifikowały fragment regionu ITS-2 rDNA. Przeprowadzone doświadczenia potwierdziły wysoką skuteczność zaprojektowanych starterów do odróżniania patogenicznych i niepatogenicznych populacji kwarantannowego nicienia B. xylophilus.

Słowa kluczowe: Bursaphelenchus xylophilus; wirulencja; real-time PCR-HRM; choroba więdnięcia sosny; nicień kwarantannowy; wykrywanie

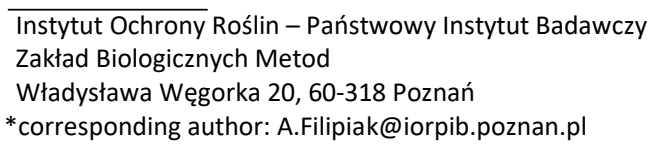




\section{Wstęp / Introduction}

Bursaphelenchus xylophilus jest czynnikiem sprawczym choroby więdnięcia sosny, doprowadzającym do zamierania drzew sosnowych na kontynencie azjatyckim, a od 1999 roku również w Europie (Portugalia i Hiszpania) (Mota i wsp. 1999; Robertson i wsp. 2011). Dotychczasowe badania prowadzone nad patogenicznością nicienia B. $x y$ lophilus wykazały, że nie wszystkie izolaty tego szkodnika doprowadzają do zamierania drzew. W obrębie jego populacji stwierdzono występowanie patogenicznych, jak i całkowicie niepatogenicznych jego izolatów, które nie powodują obumierania drzew (Kiyohara i Bolla 1990; Wang i wsp. 2005; Aikawa i Kikuchi 2007). W obrębie populacji B. xylophilus stwierdzono także takie, które charakteryzują się występowaniem samic $\mathrm{z}$ wyrostkiem na końcu ogona, tzw. mukronem. Typowe samice kwarantannowego nicienia B. xylophilus posiadają zaokrąglony ogon. Badania nad patogenicznoscią populacji zawierających taki wyrostek wykazały, że charakteryzują się one różną wirulencją w stosunku do roślin, tzn. w ich obrębie można wyróżnić zarówno izolaty, które powodują zamieranie roślin, jak również takie, które nie powodują ich obumierania (Braasch i wsp. 2001; Penas i wsp. 2004; Fonseca i wsp. 2008; Gu i wsp. 2011).

Morfologiczne odróżnienie poszczególnych populacji charakteryzujących się różną patogenicznością jest całkowicie niemożliwe, gdyż zarówno osobniki młodociane, jak i dorosłe (tj. samce i samice) wyglądają identycznie. W związku z zaistniałymi trudnościami, poszukiwane są metody molekularne umożliwiające jak najbardziej precyzyjne odróżnienie poszczególnych populacji od siebie. Dotychczas nie opracowano żadnej molekularnej metody umożliwiającej odróżnienie populacji patogenicznych od niepatogenicznych tego kwarantannowego nicienia.

W przeprowadzonych badaniach do odróżniania patogenicznych i niepatogenicznych populacji tego kwarantannowego nicienia wykorzystano reakcję real-time PCR-HRM (Polymerase Chain Reaction-High Resolution Melting). W technice tej, podobnie jak w przypadku real-time PCR, wykorzystuje się analizę topnienia produktu
PCR. Dzięki zastosowaniu barwników fluorescencyjnych możliwe jest wykrycie pojedynczych różnic nukleotydowych w porównywanych produktach PCR, przez co uzyskuje się więcej informacji na temat produktu PCR, niż było to możliwe przy zastosowaniu innych technik. Ponadto, metoda ta nie wymaga dodatkowego trawienia enzymami restrykcyjnymi (jak PCR-RFLP - Polymerase Chain Reaction-Restriction Fragment Length Polymorphism - reakcja łańcuchowej polimerazy z analizą polimorfizmu długości fragmentów restrykcyjnych) i rozdziału elektroforetycznego, co znacznie przyspiesza uzyskanie wyników (Wittwer i wsp. 2003; Pasay i wsp. 2008).

Technika real-time PCR-HRM wielokrotnie wykorzystywana była do identyfikacji innych gatunków organizmów, w tym także nicieni (Senapin i wsp. 2010; Panichareon i wsp. 2011; Holterman i wsp. 2012; Demeler i wsp. 2013). Ponadto, w ostatnim czasie technikę tę $\mathrm{z}$ powodzeniem zastosowano do identyfikacji i odróżnienia $B$. xylophilus od najbliżej spokrewnionego $\mathrm{z}$ nim morfologicznie gatunku nicienia B. mucronatus (Filipiak i Hasiów-Jaroszewska 2016).

\section{Materiały i metody / Materials and methods}

W przeprowadzonych badaniach wykorzystano osiem patogenicznych oraz dwie niepatogeniczne (obecnie, jedyne udostępnione do badań) populacje B. xylophilus pochodzące z różnych rejonów świata (tab. 1).

DNA nicieni izolowano z pojedynczych osobników (tj. osobno z samic, samców i osobników larwalnych) przy zastosowaniu zestawu QIAamp DNA Micro Kit (QIAGEN) zgodnie z zaleceniami producenta. Dla DNA badanych populacji zaprojektowano własne startery, które amplifikowały fragment regionu internal transcribed spacer (ITS)-2 rDNA (forward: 5'-CAGAAACGCCGACTTGTTTT-3' oraz reverse 5'-ATATTGGTCGCGGAACAAAC-3') (rys. 1). Startery zaprojektowano przy pomocy programu komputerowego Primer3web version 4.0.0 - Pick primers from a DNA sequence (http://bioinfo.ut.ee/primer3/) (Koressaar i Remm 2007; Untergasser i wsp. 2012).

Tabela 1. Pochodzenie populacji Bursaphelenchus xylophilus wykorzystanych w badaniach oraz numery akcesyjne ich sekwencji zdeponowanych w GenBanku

Table 1. Origin of nematode species and isolates used in the study and their GenBank accession numbers

\begin{tabular}{l|c|c|c}
\hline $\begin{array}{c}\text { Forma patogeniczności } \\
\text { Virulent form }\end{array}$ & $\begin{array}{c}\text { Nazwa izolatu } \\
\text { Isolate name }\end{array}$ & $\begin{array}{c}\text { Pochodzenie izolatu } \\
\text { Geographical origin }\end{array}$ & $\begin{array}{c}\text { Numer akcesyjny w Banku } \\
\text { Genów GenBank } \\
\text { GenBank accession No. }\end{array}$ \\
\hline & China & Nanjing, Chiny - China & KM657966 \\
& Ne $21 / 02$ & Nanjing, Chiny - China & KX8581989 \\
Ka4 & Ibaraki, Japonia - Japan & AB277206 \\
Patogeniczne & S10 & Iwimane, Japonia - Japan & AB277207 Japonia - Japan \\
Pathogenic & KR-3(w) & Korea - Korea & JN581988 \\
& BxPt67OL & Portugalia - Portugal & KX8563843 \\
\hline Niepatogeniczne & BxMad25C & Madeira, Portugalia - Portugal & AB277203 \\
Nonpathogenic & C14-5 & Chiba, Japonia - Japan & AB277205 \\
\hline
\end{tabular}




\section{BxT4 \\ BxChina \\ BXKR - 3(w) \\ BxNe2102 \\ BxPt670L \\ BxS10 \\ BxKa4 \\ BxMad25C \\ BxC14 - 5 \\ BXOKD - 1}

BxT4

BxChina

BXKR-3(w)

BxNe2102

BxPt670L

BxS10

BxKa4

BxMad25C

BxC14 - 5

BXOKD - 1

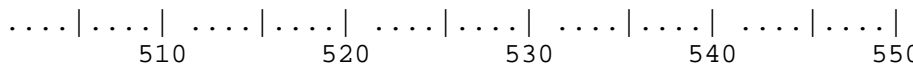

CAGAAACGCC GACTTGTTTT TTTCAAGTTT CTGCACGTTG TGACAGTCGT

CAGAAACGCC GACTTGTTTT TTTCAAGTTT CTGCACGTTG TGACAGTCGT

CAGAAACGCC GACTTGTTTT TTTCAAGTTT CTGCACGTTG TGACAGTCGT

CAGAAACGCC GACTTGTTTT TTTCAAGTTT CTGCACGTTG TGACAGTCGT

CAGAAACGCC GACTTGTTTT TTTCAAGTTT CTGCACGTTG TGACAGTCGT

CAGAAACGCC GACTTGTTTT TTTCAAGTTT CTGCACGTTG TGACAGTCGT

CAGAAACGCC GACTTGTTTT TTTCAAGTTT CTGCACGTTG TGACAGTCGT

CAGAAACGCC GACTTGTTTT TTTCAAGTTT CTGCACGTTG TGACAGTCGT

CAGAAACGCC GACTTGTTTT TTTCAAGTTT CTGCACGTTG TGACAGTCGT CAGAAACGCC GACTTGTTTT TTTCAAGTTT CTGCACGTTG TGACAGTCGT forward primer

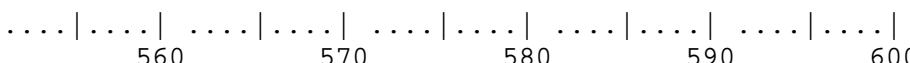

CTCGCATTGT TCGCGCAATG TTAGGCACCA TCTGTTTTAC GCGGTTTGTT

CTCGCATTGT TCGCGCAATG TTAGGCACCA TCTGTTTTAC GCGGTTTGTT

CTCGCATTGT TCGCGCAATG TTAGGCACCA TCTGTTTTAC GCGGTTTGTT

CTCGCATTGT TCGCGCAATG TTAGGCACCA TCTGTTTTAC GCGGTTTGTT

CTCGCATTGT TCGCGCAATG TTAGGCACCA TCTGTTTTAC GCGGTTTGTT

CTCGCATTGT TCGCGCAATG TTAGGCACCA TCTGTTTTAC GCGGTTTGTT

CTCGCATTGT TCGCGCAATG TTAGGCACCA TCTGTTTTAC GCGGTTTGTT

CTCGCATTGT TCGCGCAATG TTAGGCACCA TCTGTTTTAC GCGGTTTGTT

CTCGCATTGT TCACGCAATG TTAGGCACCA TCTGTTTTAC GCGGTTTGTT

CTCGCATTGT TCACGCAATG TTAGGCACCA TCTGTTTTAC GCGGTTTGTT

$$
\ldots|\ldots|
$$

$$
610
$$

BxT4

CCGCGACCAA TAT

CCGCGACCAA TAT

CCGCGACCAA TAT

CCGCGACCAA TAT

CCGCGACCAA TAT

CCGCGACCAA TAT

CCGCGACCAA TAT

CCGCGACCAA TAT

CCGCGACCAA TAT

CCGCGACCAA TAT

reverse primer

Rys. 1. Diagram ukazujący sekwencje nukleotydów startera forward i reverse oraz zidentyfikowaną różnicę w sekwencji amplikonu pomiędzy populacjami patogenicznymi i niepatogenicznymi Bursaphelenchus xylophilus

Fig. 1. Diagram indicating the nucleotide sequences of the forward and reverse primer and the identified sequence single nucleotide polymorphism (SNP) differentiating virulent and avirulent populations of Bursaphelenchus xylophilus

Mieszanina reakcyjna zawierała: $1 \mu \mathrm{l}$ DNA (stężenie 30-50 ng/ $\mu \mathrm{l}), 1 \mu \mathrm{l}$ startera forward $10 \mu \mathrm{mol} / \mu \mathrm{l}, 1 \mu \mathrm{l}$ startera reverse $10 \mu \mathrm{mol} / \mu \mathrm{l}, 2,5 \mathrm{mM} \mathrm{MgCl}$ oraz $10 \mu \mathrm{l}$ buforu LightCycler ${ }^{\circledR} 480$ High Resolution Melting Master (Roche Diagnostics). Całość uzupełniano wodą do objętości $20 \mu \mathrm{l}$. Reakcje PCR-HRM prowadzono w następujących warunkach: początkowa denaturacja $\mathrm{w}$ temperaturze $95^{\circ} \mathrm{C}$ przez 10 minut, 50 cykli: denaturacja w temperaturze $95^{\circ} \mathrm{C}$ przez 15 sekund, przyłączanie starterów w temperaturze $60^{\circ} \mathrm{C}$ przez 15 sekund oraz wydłużanie w temperaturze $72^{\circ} \mathrm{C}$ przez 20 sekund. Reakcje przeprowadzano w aparacie LightCycler ${ }^{\circledR} 480$ Software, Version 1.5. Otrzymane dane analizowane były zgodnie $\mathrm{z}$ instrukcjami producenta.

\section{Wyniki i dyskusja / Results and discussion}

Przeprowadzone, wcześniejsze badania nad nicieniem B. xylophilus wykazały znaczne różnice genetyczne, a także $\mathrm{w}$ patogeniczności pomiędzy populacjami tego kwarantannowego szkodnika (Braasch i wsp. 1995; Irdani i wsp. 1995; Zhang i wsp. 2002; Vieira i wsp. 2007). Roz- różnienie populacji patogenicznych od niepatogenicznych tego nicienia jest niemożliwe, dlatego poszukiwane są metody molekularne. W przeprowadzonych badaniach do odróżniania dwóch wirulentnych form B. xylophilus wykorzystano reakcję real-time PCR-HRM. Zaletą tej techniki jest możliwość odróżnienia dwóch badanych gatunków lub populacji na podstawie pojedynczych mutacji występujących pomiędzy nimi (Wittwer i wsp. 2003; Pasay i wsp. 2008). Wykryta mutacja występująca w regionie zmiennym ITS-2 pomiędzy populacjami patogenicznymi i niepatogenicznymi $B$. xylophilus umożliwiła wykorzystanie tej techniki do rozróżniania dwóch wiruletnych form tego nicienia. W niektórych populacjach B. xylophilus w obrębie tego regionu występują inne, dodatkowe mutacje. Są one jednak charakterystyczne dla populacji tego nicienia obejmujących samice wyróżniające się charakterystycznym wyrostkiem na końcu ogona (Braasch i wsp. 2001; Penas i wsp. 2004; Fonseca i wsp. 2008; Gu i wsp. 2011).

Przeprowadzone doświadczenia potwierdziły skuteczność zaprojektowanych starterów do powielania wybranych fragmentów DNA, które umożliwiają odróżnianie patogenicznych od niepatogenicznych populacji kwaran- 
tannowego nicienia B. xylophilus. Analiza krzywej topnienia produktów reakcji wykazała obecność pojedynczego produktu amplifikacji dla każdej z przeprowadzonych reakcji (rys. 2).

Uzyskane podczas analizy HRM znormalizowane krzywe topnienia DNA różniły się pomiędzy sobą temperaturą denaturacji, o czym świadczą znaczne przesunięcia tych krzywych względem siebie. Wskazuje to na obecność różnic w składzie nukleotydowym badanych gatunków nicieni w amplifikowanym rejonie genomu (rys. 3).
Zaprojektowane startery pozwalały na amplifikację produktów umożliwiających odróżnienie dwóch różnych wirulentnych form $B$. xylophilus, co potwierdzone zostało również na wykresie różnicującym patogeniczne i niepatogeniczne populacje tego szkodnika (rys. 4).

Zarówno reakcje DNA wyizolowanym z populacji nicieni, jak i z pojedynczych osobników (bez względu na stadium rozwojowe) pozwalały na wyraźne odróżnienie od siebie populacji tego nicienia charakteryzujących się różną patogenicznością.

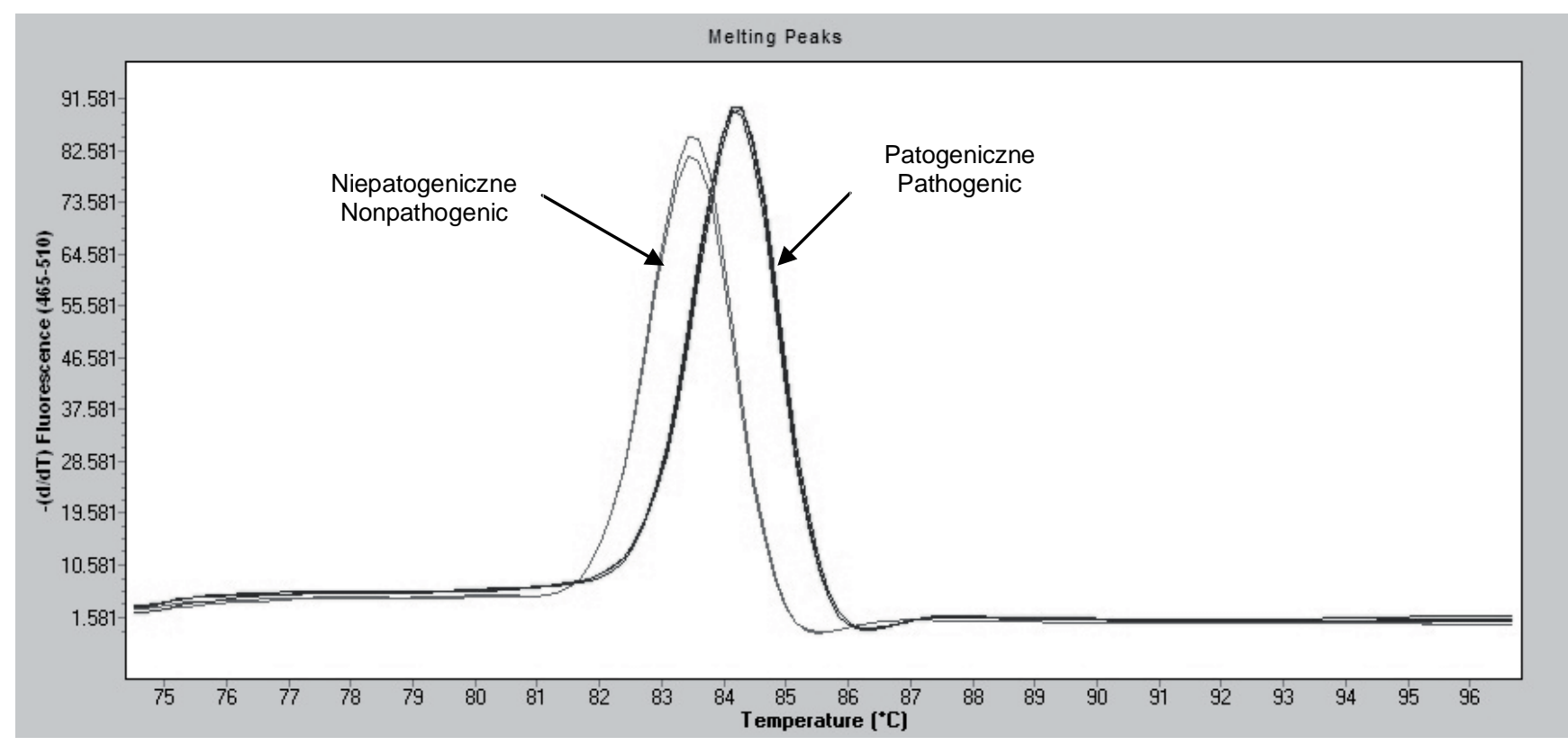

Rys. 2. Krzywe topnienia produktów reakcji PCR-HRM dla patogenicznych (China, Ka4 oraz T4) i niepatogenicznych (C14-5 oraz OKD-1) populacji Bursaphelenchus xylophilus

Fig. 2. Melting curves of real-time PCR-HRM products for pathogenic (China, Ka4 and T4) and nonpathogenic (C14-5 and OKD-1) populations of Bursaphelenchus xylophilus

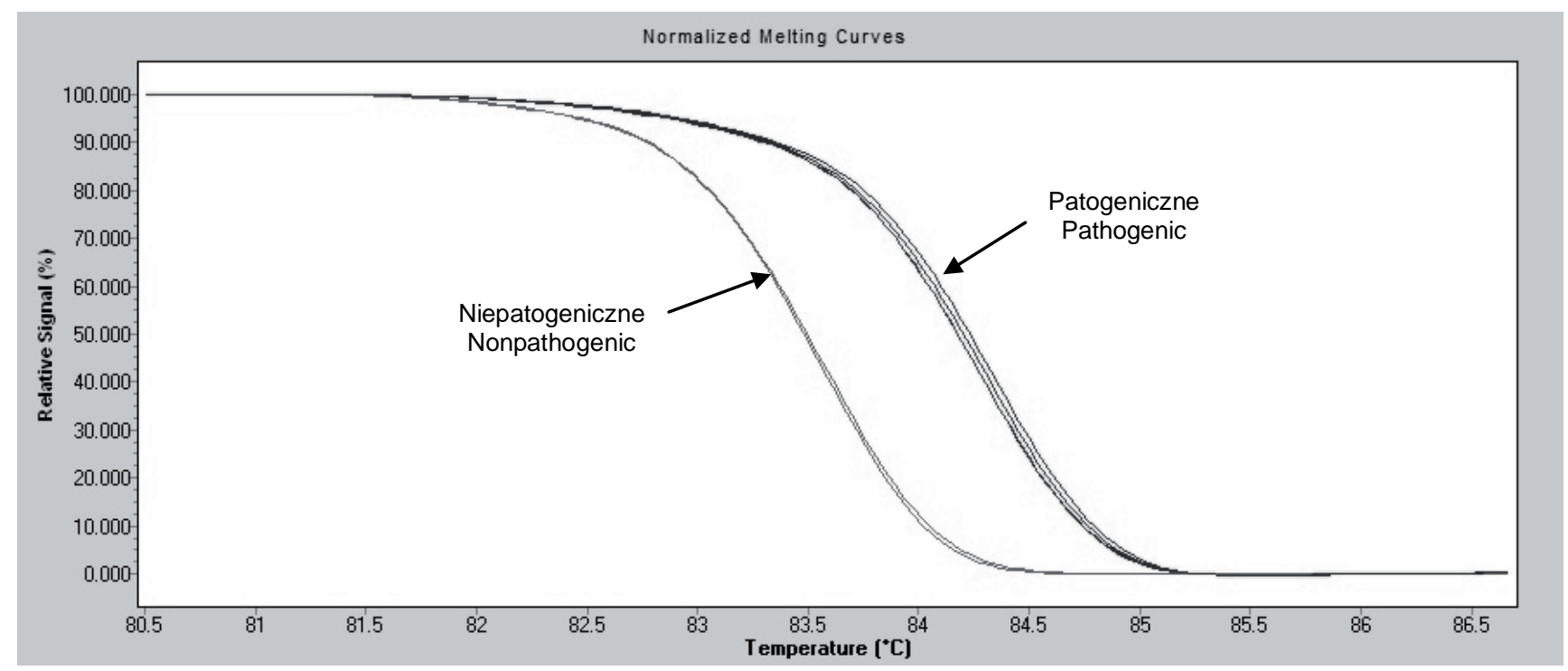

Rys. 3. Znormalizowany wykres fluorescencji różnicujący produkty reakcji PCR-HRM dla patogenicznych (China, Ka4 oraz T4) i niepatogenicznych (C14-5 oraz OKD-1) populacji Bursaphelenchus xylophilus

Fig. 3. Normalized melting curves of real-time PCR-HRM products for pathogenic (China, Ka4 and T4) and nonpathogenic (C14-5 and OKD-1) populations of Bursaphelenchus xylophilus 


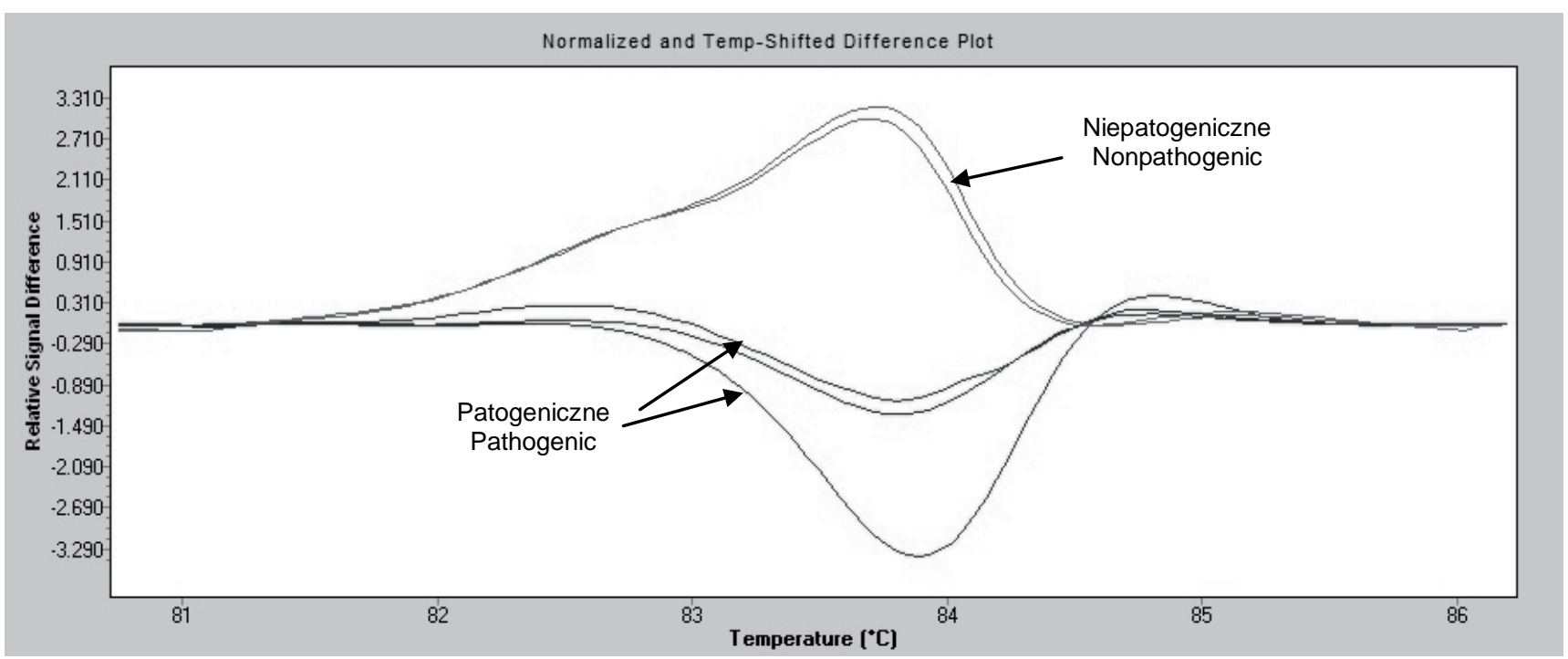

Rys. 4. Wykres różnicujący produkty reakcji PCR-HRM dla patogenicznych (China, Ka4 oraz T4) i niepatogenicznych (C14-5 oraz OKD-1) populacji Bursaphelenchus xylophilus

Fig. 4. Differential plot of real-time PCR-HRM products for pathogenic (China, Ka4 and T4) and nonpathogenic (C14-5 and OKD-1) populations of Bursaphelenchus xylophilus

Reakcja PCR-HRM umożliwia wykrycie nawet pojedynczych zmian nukleotydowych w badanych produktach PCR, dzięki czemu może być bardzo przydatną metodą wspomagającą i rozstrzygającą w przypadku identyfikacji bardzo blisko ze sobą spokrewnionych gatunków i izolatów dających niejednoznaczne rezultaty $\mathrm{w}$ reakcji real-time PCR. W porównaniu do innych metod molekularnych, technika PCR-HRM może być dużo prostszym i znacznie tańszym sposobem identyfikowania i różnicowania kwarantannowego szkodnika B. xylophilus.

\section{Wnioski / Conclusions}

1. Przeprowadzone badania wykazały, że reakcja PCR-HRM umożliwia łatwe odróżnienie patogenicznych od niepatogenicznych populacji B. xylophilus.
2. Metoda ta jest bardzo czuła i pozwala na wykrycie różnic nawet w pojedynczych nukleotydach.

3. Analiza PCR-HRM jest również znacznie tańsza w porównaniu do powszechnie stosowanej techniki PCR-RFLP.

\section{Podziękowania / Acknowledgements}

Autorka pragnie podziękować pracownikom Międzyzakładowej Pracowni Biologii Molekularnej oraz Zakładowi Wirusologii i Bakteriologii Instytutu Ochrony Roślin - Państwowego Instytutu Badawczego za udostępnienie części wykorzystanego w badaniach sprzętu oraz cenne wskazówki udzielone w czasie realizacji prac i interpretacji wyników.

\section{Literatura / References}

Aikawa T., Kikuchi T. 2007. Estimation of virulence of Bursaphelenchus xylophilus (Nematoda: Aphelenchoididae) based on its reproductive ability. Nematology 9 (3): 371-377. DOI: 10.1163/156854107781352007.

Braasch H., Burgermeister W., Pastrik K. 1995. Differentiation of three Bursaphelenchus species by means of RAPD-PCR. Nachrichtenblatt des Deutschen Pflanzenschutzdiensts 47: 310-314.

Braasch H., Tomiczek Ch., Metge K., Hoyer U., Burgermeister W., Wulfert I., Schönfeld U. 2001. Records of Bursaphelenchus spp. (Nematoda, Parasitaphelenchidae) in coniferous timber imported from the Asian part of Russia. Forest Pathology 31: 129-140. DOI: 10.1046/j.1439-0329.2001.00233.x.

Demeler J., Ramünke S., Wolken S., Ianiello D., Rinaldi L., Gahutu J.B., Cringoli G., von Samson-Himmelstjerna G., Krücken J. 2013. Discrimination of gastrointestinal nematode eggs from crude fecal egg preparations by inhibitor-resistant conventional and real-time PCR. PLoS ONE 8(4): e61285. DOI: 10.1371/journal.pone.0061285.

Filipiak A., Hasiów-Jaroszewska B. 2016. The use of real-time polymerase chain reaction with high resolution melting (real-time PCR-HRM) analysis for the detection and discrimination of the quarantine nematode Bursaphelenchus xylophilus and Bursaphelenchus mucronatus. Molecular and Cellular Probes 30 (2): 113-117. DOI: 10.1016/j.mcp.2016.02.003.

Fonseca L., dos Santos M.C.V., Santos M.S.N.A., Curtis R.H.C., Abrantes I.M.O. 2008. Morphobiometrical characterisation of Portuguese Bursaphelenchus xylophilus isolates with mucronate, digitate or round tailed females. Phytopathologia Mediterranea 47: $223-233$.

Gu J., Wang J., Braasch H., Burgermeister W., Schroeder T. 2011. Morphological and molecular characterisation of mucronate isolates ('M' form) of Bursaphelenchus xylophilus (Nematoda: Aphelenchoididae). Russian Journal of Nematology 19: 103-120.

Holterman M.H.M., Oggenfuss M., Frey J.E., Kiewnick S. 2012. Evaluation of high-resolutionmelting curve analysis as a new tool for root-knot nematode diagnostics. Journal of Phytopathology 160: 59-66. 
Irdani T., Caroppo S., Ambrogioni L. 1995. Molecular identification of pine wood Bursaphelenchus species. Nematologia Mediterranea 23: 99-106.

Kiyohara T., Bolla R.I. 1990. Pathogenic variability among populations of the pinewood nematode, Bursaphelenchus xylophilus. Forest Science 36 (4): 1061-1076.

Koressaar T., Remm M. 2007. Enhancements and modifications of primer design program Primer3. Bioinformatics 23 (10): $1289-1291$.

Mota M.M., Braasch H., Bravo M.A., Penas A.C., Burgermeister W., Metge K., Sousa E. 1999. First report of Bursaphelenchus xylophilus in Portugal and in Europe. Nematology 1 (7-8): 727-734.

Panichareon B., Khawsak P., Deesukon W., Sukhumsirichart W. 2011. Multiplex real-time PCR and high-resolution melting analysis for detection of White spotsyndrome virus, Yellow-head virus, and Penaeus monodon densovirus in penaeidshrimp. Journal of Virological Methods 178 (1-2): 16-21. DOI: 10.1016/j.jviromet.2011.07.010.

Pasay C., Arlian L., Morgan M., Vyszenski-Moher D., Rose A., Holt D., Walton S., McCarthy J. 2008. High-resolution melt analysis for the detection of a mutation associated with permethrin resistance in a population of scabies mites. Medical and Veterinary Entomology 22 (1): 82-88. DOI: 10.1111/j.1365-2915.2008.00716.x.

Penas A.C., Correia P., Bravo M.A., Mota M., Tenreiro R. 2004. Species of Bursaphelenchus Fuchs, 1937 (Nematoda: Parasitaphelenchidae) associated with maritime pine in Portugal. Nematology 6 (3): 437-453.

Robertson L., Cobacho Arcos S., Escuer M., Santiago Merino R., Esparrago G., Abelleira A., Navas A. 2011. Incidence of the pinewood nematode Bursaphelenchus xylophilus Steiner \& Buhrer, 1934 (Nickle, 1970) in Spain. Nematology 13 (6): 755-757.

Senapin S., Molthathong S., Phiwasaiya K., Jaengsanong C., Chuchird N. 2010. Application of high resolution melt (HRM) analysis for duplex detection of Macrobrachium rosenbergii nodavirus (MrNV) and extra small virus (XSV) in shrimp. Molecular and Cellular Probes 24 (5): 291-297.

Untergasser A., Cutcutache I., Koressaar T., Ye J., Faircloth B.C., Remm M., Rozen S.G. 2012. Primer3 - new capabilities and interfaces. Nucleic Acids Research 40 (15): e115. DOI: 10.1093/nar/gks596.

Vieira P., Burgermeister W., Mota M., Metge K., Silva G. 2007. Lack of genetic variation of Bursaphelenchus xylophilus in Portugal revealed by RAPD-PCR analyses. Journal of Nematology 39 (2): 118-126.

Wang Y., Yamada T., Sakaue D., Suzuki K. 2005. Variations on the life history parameters and their influence on rate of population increase of different pathogenic isolates of the pine wood nematode, Bursaphelenchus xylophilus. Nematology 7 (3): $459-467$.

Wittwer C.T., Reed G.H., Hundry C.N., Vandersteen J.G., Pryor R.J. 2003. High-resolution genotyping by amplicons melting analysis using LC green. Clinical Chemistry 49 (6): 853-860.

Zhang L., Kong F., Yang B. 2002. Intra and interspecific variation in Bursaphelenchus xylophilus and B. mucronatus revealed by mtDNA polymorphism. Forest Research 15: 7-12. 